\title{
Prevalence of Endometrial Proliferation in Pipelle Biopsies in Tamoxifen-Treated Postmenopausal Women with Breast Cancer in Kuwait
}

\author{
M. Al-Azemi a,b N.S. Labib ${ }^{b}$ M.M.M. Motawy ${ }^{c} \quad$ L. Temmim $^{c}$ \\ M.A.A. Moussad A.E. Omu ${ }^{a, b}$ \\ aDepartment of Obstetrics and Gynecology, Faculty of Medicine, Kuwait University, b Maternity Hospital, \\ cKuwait Cancer Control Center, dDepartment of Community Medicine, Faculty of Medicine, \\ Kuwait University, Kuwait
}

\section{Key Words}

Breast cancer - Tamoxifen · Screening - Endometrial pathology

\begin{abstract}
Objective: To determine the prevalence of pathologic changes in the endometrium of tamoxifen-treated asymptomatic postmenopausal patients with breast cancer. Subjects and Methods: Fifty postmenopausal asymptomatic breast cancer patients with positive estrogen receptor status were treated with $20 \mathrm{mg}$ of tamoxifen daily for a period of 5-60 months. The control group consisted of 30 asymptomatic postmenopausal breast cancer patients who were negative for estrogen receptor and therefore did not receive tamoxifen. Endometrial biopsies were performed using Pipelle endometrial suction curette at least 5 months after the study began. The endometrium was classified as atrophic (negative finding) and proliferative or hyperplastic (positive findings). The study and control groups were compared for demographic characteristics, risk factors for endometrial cancer, histological findings and the duration of tamoxifen
\end{abstract}

treatment. Results: A significantly greater prevalence of endometrial abnormalities existed among the tamoxifen-treated than control patients (76 vs. $33 \%, p<0.001$ ). The abnormal endometrial changes were further demarcated in both groups into proliferative (54 vs. $26.7 \%, p=$ 0.02 ) and hyperplastic ( 22 vs. $6.6 \%, p=N S$ ). In the study group, $63.6 \%$ of hyperplastic endometrium was simple hyperplasia and $36.4 \%$ was complex/no atypia hyperplasia, while in the control group all the cases were simple hyperplasia. No endometrial cancer was detected in either group. In addition, there was a positive association between the duration of tamoxifen exposure $(<1$ year vs. $\geq 1$ year) and the endometrial abnormalities (46.6 vs. $88.6 \%, p=0.003$; proliferative 57.1 vs. $74.1 \%, p=0.015$; hyperplastic 42.8 vs. $25.8 \%, p=N S$ ). Conclusion: The adjuvant use of tamoxifen is associated with significant time-dependent abnormal endometrial changes among patients with cancer of the breast.

Copyright @ 2004 S. Karger AG, Basel

\begin{tabular}{ll}
\hline KARGER & ( ) 2004 S. Karger AG, Basel \\
Fax +41 61306 1234 & 1011-7571/04/0131-0030\$21.00/0 \\
$\begin{array}{l}\text { E-Mail karger@karger.ch } \\
\text { www.karger.com }\end{array}$ & $\begin{array}{l}\text { Accessible online at: } \\
\text { www.karger.com/mpp }\end{array}$
\end{tabular}

\author{
Majedah Al-Azemi, Assistant Professor \\ Department of Obstetrics and Gynecology \\ Faculty of Medicine, PO Box 24923 \\ KW-13110 Safat (Kuwait)
}

Tel. +965 5319601, Fax +965 5338906, E-Mail alazemimajda@hsc.kuniv.edu.kw 


\section{Introduction}

With an incidence of 15.1 per 100,000 women, breast cancer is the most common malignant tumor among women in Kuwait and accounts for $27.6 \%$ of all female cancers [1]. Tamoxifen, a nonsteroidal triphenylethylene derivative, is widely used as adjuvant therapy for breast cancer in postmenopausal patients [2]. It has agonist and antagonist effects depending on the target tissues. The predominant antiestrogen activity is on the breast, while it produces estrogenic stimulatory effects on the endometrium, such as hyperplasia, endometrial polyps, and endometrial carcinoma [2-9]. It has been shown that tamoxifen-treated patients have an increased risk (1.3-7.5) of developing endometrial cancer [10]. In the National Surgical Adjuvant Breast Project Trial [4], women with stage I breast cancer who received adjuvant tamoxifen treatment at $20 \mathrm{mg}$ daily for up to 5 years and women at high risk but with no malignancy in chemoprevention trials were shown to be at approximately 7 times greater risk for endometrial cancer than controls.

The long-term endometrial sequelae of tamoxifen treatment have raised concerns about monitoring the endometrium of all women receiving the drug $[11,12]$. However, there is considerable uncertainty about the most effective and acceptable method of monitoring the endometrium. The techniques most frequently advocated are transvaginal sonography and hysteroscopy, supplemented by endometrial biopsy [13]. Transvaginal sonography may not be sensitive enough to detect endometrial polyps without additional procedures such as intracavity saline instillation. Hysteroscopy is valuable for detection of focal lesions, but less so in the evaluation of generalized endometrial hyperplasia and obtaining a representative biopsy by curettage [14]. Pipelle endometrial suction is a simple and remarkably less expensive method than both transvaginal sonography and hysteroscopy. Hence, we decided to use Pipelle endometrial suction to determine the incidence of pathologic changes in the endometrium of postmenopausal breast cancer patients treated with tamoxifen.

\section{Subjects and Methods}

Between October 1997 and October 1999, 80 breast cancer patients being treated at the Kuwait Cancer Control Center (KCCC) agreed to participate in this study. Breast cancer is managed at the KCCC using a standard protocol, according to $\mathrm{T}$ (size of the primary tumor), $\mathrm{N}$ (regional lymph node involvement) and M (distant metastasis) classification [15], and also according to the estrogen- and pro- gesterone-receptor status. The study group consisted of 50 asymptomatic postmenopausal breast cancer patients with positive estrogen receptor status who were treated with $20 \mathrm{mg}$ of tamoxifen daily for a period of 5-60 months (mean of $20.2 \pm 15.8$ months). The control group consisted of 30 asymptomatic postmenopausal breast cancer patients who were negative for estrogen receptor and therefore were not given tamoxifen treatment. The study was approved by the Ethics Committee at KCCC, and informed consent was obtained from each patient after full explanation of the objectives of the study.

All patients underwent endometrial biopsy using Pipelle endometrial suction curette, at least 5 months after entering the study. Endometrial biopsy was prepared by initial fixation in $10 \%$ formalin for $24 \mathrm{~h}$, processed in 'Path-Shandon', and embedded in the 'Shandon Histocenter' (Shandon, Runcorn, Cheshire, UK) to make paraffin blocks. Cutting was performed in $5-\mu \mathrm{m}$ slides, followed by staining in hematoxylin and eosin. A minimum set of 3 slides was given to the pathologist for examination. All biopsies were evaluated histologically by 2 senior oncological pathologists at the KCCC. Tissue fragments were examined under light microscopy and the endometrium was classified as atrophic, proliferative, or hyperplastic. In postmenopausal women, the endometrium is expected to be atrophic due to the absence of estrogen effect. Therefore, atrophic endometrium was regarded as a negative finding. Proliferative and hyperplastic endometrium were considered as positive findings because these changes reflect an estrogenic effect on the endometrium.

The study and control groups were compared for the following: demographic characteristics, risk factors for endometrial cancer (age, parity, hypertension, diabetes, body mass index (BMI), histological findings and the duration of tamoxifen treatment.

\section{Statistical Analysis}

The normal-Z test was used to assess the significance for the difference between two proportions. The cutoff level for the statistical significance was $p<0.05$. The results were analyzed with MannWhitney nonparametric methods.

\section{Results}

The demographic characteristics and risk factors for endometrial cancer are compared in table 1 . There were no statistically significant differences between the groups in age ( $55 \pm 9.1$ vs. $51.8 \pm 7.2$ years $)$ or incidence of the known endometrial cancer risk factors of parity, hypertension, diabetes mellitus, and obesity (BMI evaluation).

As shown in table 2, 38 women (76\%) in the tamoxifen-treated group had positive endometrial pathology compared to $10(33.3 \%)$ in the untreated group and the difference was statistically significant $(\mathrm{p}<0.001)$. Further breakdown of the positive results into proliferative and hyperplastic endometrium revealed a significant difference in the occurrence of proliferative endometrium between the two groups $(\mathrm{p}<0.05)$, with $27(54 \%)$ treated compared to $8(26.7 \%)$ untreated patients. However, although more patients $(22 \%)$ in the treatment group 
compared to the untreated group (6.6\%) had hyperplastic endometrium, the difference was not statistically significant $(p=0.07)$. Of the 11 cases of hyperplastic endometrium in the study group, 7 were simple hyperplasia while 4 were complex/no atypia. The control group had 2 cases of simple hyperplasia and no complex hyperplasia. No endometrial cancer was detected in either group.

A comparison between the duration of tamoxifen treatment and the frequency of endometrial pathology

Table 1. Demographic characteristics and risk factors for breast cancer patients treated (study group) and not treated (control group) with tamoxifen

\begin{tabular}{llll}
\hline $\begin{array}{l}\text { Demographic } \\
\text { characteristics }\end{array}$ & $\begin{array}{l}\text { Study group } \\
(\mathrm{n}=50)\end{array}$ & $\begin{array}{l}\text { Control group } \\
(\mathrm{n}=30)\end{array}$ & $\mathrm{p}$ value \\
\hline $\begin{array}{l}\text { Age, years } \\
\quad<50\end{array}$ & 7 & 2 & $\mathrm{NS}$ \\
$\quad 50-60$ & 35 & 17 & $\mathrm{NS}$ \\
$\quad>60$ & 8 & 11 & $\mathrm{NS}$ \\
$\quad$ Means \pm SD & $55 \pm 9.1$ & $51.8 \pm 7.2$ & $\mathrm{NS}$ \\
Parity & & & \\
$\quad 0$ & 7 & 2 & $\mathrm{NS}$ \\
$\quad 1-3$ & 38 & 20 & $\mathrm{NS}$ \\
$\quad>4$ & 5 & 8 & $\mathrm{NS}$ \\
Hypertension & 10 & 4 & $\mathrm{NS}$ \\
Diabetes & 8 & 4 & $\mathrm{NS}$ \\
BMI & & & \\
$\quad 18-25$ & 7 & 3 & $\mathrm{NS}$ \\
$26-30$ & 30 & 18 & $\mathrm{NS}$ \\
$>30$ & 13 & 9 & $\mathrm{NS}$ \\
Means \pm SD & $34 \pm 5.2$ & $33.2 \pm 4.3$ & $\mathrm{NS}$ \\
\hline
\end{tabular}

$\mathrm{NS}=$ Not significant $; \mathrm{p}>0.05$ was conducted after subdividing the tamoxifen-treated group into those treated for less than 1 year and those for 1 year or longer (table 3). There was a significant timedependent increase in positive endometrial finding: $7 / 15$ (46.6\%) for less than 1 year, compared to $31 / 35$ (88.8\%, $\mathrm{p}=0.003$ ) after more than 1 year of treatment. There was a statistically significant difference in the proliferative endometrium between less than (4/7) and more than (23/ 31) 1 year of treatment $(p=0.015)$, while the hyperplastic endometrium did not show any significant difference. Of the 3 cases of hyperplasia in patients treated with tamoxifen for less than 1 year, 2 were simple hyperplasia and 1 complex/no atypia, while in those treated for more than 1 year, 5 were simple hyperplasia and 3 were complex/no atypia.

\section{Discussion}

In this study, although there was generally a higher incidence of endometrial pathology in the tamoxifentreated $(76 \%)$ than in the untreated $(33 \%)$ group of patients, endometrial cancer was not detected in either group. Since Pipelle endometrial suction may not pick up all of the polyps and some of them might harbor endometrial cancer, the clinical utility of screening tamoxifentreated patients with routine office biopsy becomes questionable, as pointed out by Barakat et al. [16]. Hence, it is necessary that other methods like hysteroscopy and directed endometrial sampling be carried out in patients who are symptomatic with vaginal bleeding and discharge $[12,14]$.

The statistically significant difference in the frequency of positive histological endometrial changes among the
Table 2. Histopathological (HP) analysis of the endometrium from patients treated (study group) and not treated (control group) with tamoxifen

\begin{tabular}{llllll}
\hline HP diagnosis & $\begin{array}{l}\text { Study group } \\
(\mathrm{n}=50)\end{array}$ & $\begin{array}{l}\text { Control } \\
\text { group } \\
(\mathrm{n}=30)\end{array}$ & $\begin{array}{l}\text { Odds } \\
\text { ratio }\end{array}$ & 95\% CI & p value \\
\hline Negative (atrophic) & $12(24 \%)$ & $20(66.7 \%)$ & 0.16 & $0.06-0.43$ & $<0.001$ \\
Positive & $38(76 \%)$ & $10(33.3 \%)$ & 6.33 & $2.33-17.19$ & $<0.001$ \\
Proliferative & $27(54 \%)$ & $8(26.7 \%)$ & 3.23 & $1.21-8.62$ & 0.021 \\
Hyperplastic & $11(22 \%)$ & $2(6.6 \%)$ & 3.95 & $0.81-19.23$ & NS \\
$\quad$ Simple & $7(63.6 \%)$ & $2(100 \%)$ & & & \\
$\quad$ Complex & $4(36.4 \%)$ & 0 & & & \\
$\quad$ No atypia & 4 & 0 & & & \\
$\quad$ With atypia & 0 & 0 & & & \\
\hline
\end{tabular}

NS = Not significant; $\mathrm{p}<0.05$. 
Table 3. Comparison between tamoxifen exposure and abnormalities detected in the study group

\begin{tabular}{|c|c|c|c|c|c|}
\hline HP diagnosis & $\begin{array}{l}<1 \text { year } \\
\text { exposure } \\
(n=15)\end{array}$ & $\begin{array}{l}\geq 1 \text { year } \\
\text { exposure } \\
(n=35)\end{array}$ & $\begin{array}{l}\text { Odds } \\
\text { ratio }\end{array}$ & $95 \% \mathrm{CI}$ & $\mathrm{p}$ value \\
\hline Negative (atrophic) & $8(53.4 \%)$ & $4(11.4 \%)$ & 8.86 & $2.07-37.9$ & 0.003 \\
\hline Positive & $7(46.6 \%)$ & $31(88.6 \%)$ & 0.11 & $0.03-0.48$ & 0.003 \\
\hline Proliferative & $4(57.1 \%)$ & $23(74.1 \%)$ & 0.19 & $0.05-0.72$ & 0.015 \\
\hline Hyperplastic & $3(42.8 \%)$ & $8(25.8 \%)$ & 0.84 & $0.19-3.75$ & NS \\
\hline Simple & $2(66.6 \%)$ & $5(62.5 \%)$ & & & \\
\hline Complex & $1(33.3 \%)$ & $3(37.5 \%)$ & & & \\
\hline No atypia & 1 & 3 & & & \\
\hline With atypia & 0 & 0 & & & \\
\hline
\end{tabular}

$\mathrm{NS}=$ Not significant; $\mathrm{p}<0.05$ tamoxifen-treated patients compared to the nontreated group $(\mathrm{p}<0.001)$ supports the idea that tamoxifen treatment induces endometrial proliferation, consistent with previous studies [14, 17-19]. Ismail [14] identified a dosedependent effect in a subgroup of patients who took more than $35 \mathrm{~g}$ of tamoxifen and were at increased risk of developing endometrial cancer. He postulated that the spectrum of pathological findings in these patients suggested that the drug promotes endometrial growth and the formation of endometrial polyps, which might be an intermediate step in endometrial carcinogenesis due to estrogenic agonist activity in the endometrium. Also in accordance with our findings is a study by Cohen et al. [19], in which the prevalence of endometrial pathological findings was found to be high among asymptomatic postmenopausal breast cancer patients treated with tamoxifen (35.5\%), compared with nontreated patients (20\%).

An important finding in the present study is the timedependent nature of endometrial proliferation in women treated with tamoxifen. Decensi et al. [20] demonstrated the same time-dependent proliferative effect of tamoxifen on the endometrium in an analysis of the stromal:epithelial ratio, assessment of DNA ploidy and proliferation by flow cytometry in 33 women who received $20 \mathrm{mg}$ of tamoxifen as adjuvant breast cancer treatment, as compared to 37 controls.

Although there was a high incidence of endometrial pathology in the present study, especially in tamoxifentreated women, most of the changes were endometrial proliferation, and no case of endometrial cancer was detected, which may be because the endometrial screening was conducted over a relatively short time. The findings of the present study are in accordance with the assertion that the net benefits induced by tamoxifen in breast cancer chemoprevention [21] outweigh the risk of endometrial changes. Adjuvant tamoxifen therapy lengthens disease-free survival, increases overall survival and reduces the risk of developing breast cancer in the contralateral breast [10].

A principal limitation of this study is the lack of baseline endometrial biopsy, which could have been helpful for evaluating the sensitivity and specificity of the use of the Pipelle suction curettage method for screening endometrial changes induced by tamoxifen treatment. Such a study has already been advocated [14], and we hope to embark on it in the future.

\section{Conclusion}

The adjuvant use of tamoxifen is associated with significant abnormal endometrial changes among breast cancer patients with positive estrogen receptor status. Pipelle suction curettage is a useful method for monitoring endometrial changes.

\section{Acknowledgment}

The authors are grateful to Mrs. Sobha Abraham and Mrs. Susan George for their valuable contribution in manuscript preparation and to Mrs. Asiya Tasnim for her help in statistical analysis. 


\section{References}

1 Paszko Z, Omar YT, Nasralla MY, Jazzaf H, Bouzubar L, Temmim L, Padzik H: Estrogen and progesterone receptor status in breast cancer in Kuwaiti female population. Neoplasma 1993;40:127-132.

2 Bartlett K, Eremin O, Hutcheon A, Preece P, Scott JS, Forrest P, Chetty U, Prescott RJ, Rodger A, Smyth J, George D, Habeshaw T, Kaye SB, McArdle CS, McCallum M, Smith DC, McMillan B, Robinson SM, Stewart HJ, White GK, Giles GR: Adjuvant tamoxifen in the management of operable breast cancer: The Scottish trial. Lancet 1987;ii:171-175.

3 Boccardo F, Guarneri D, Rubagotti A, Casertelli GL, Bentivoglio G, Conte N, Campanella G, Gaggero G, Comelli G, Zanardi S, et al Endocrine effects of tamoxifen in postmenopausal breast cancer patients. Tumori 1984;70: 61-68.

4 Fisher B, Costantino JP, Redmond CK: Endometrial cancer in tamoxifen-treated breast cancer patients: Findings from the National Surgical Adjuvant Breast and Bowel Project (NSABP) B-14. J Natl Cancer Inst 1994;86: 527-537.

5 Hardell L: Tamoxifen as risk factor for carcinoma of corpus uteri. Lancet 1988;iii:563.

6 Fornander T, Rutqvist LE, Cedarmark B, Glas U, Mattsson A, Silfversward C, Skoog L, Somell A, Theve T, Wilking N: Adjuvant tamoxifen in early breast cancer: Occurrence of new primary cancers. Lancet 1989;i:117-120.
7 Atlante G, Pozzi M, Vincenzoni C, Vocaturo $\mathrm{G}$ : Four case reports presenting new acquisitions on the association between breast and endometrial carcinoma. Gynecol Oncol 1990; 37:378-380.

8 Malfetano JH: Tamoxifen associated endometrial carcinoma in postmenopausal breast cancer patients. Gynecol Oncol 1990;39:82-84.

9 Mathew A, Chabon AB, Kabakow B, Drucker M, Hirschman RJ: Endometrial carcinoma in five patients with breast cancer on tamoxifen therapy. NY State J Med 1990;90:207-208.

10 Henderson IC: Should tamoxifen use be curtailed because of the risk of endometrial cancer? Breast Dis Year Book Q 1994;5:18-23.

11 Neven P, De Muyder X, Van Belle Y, Campo R, Vanderick G: Tamoxifen and the uterus (editorial). BMJ 1994;309:1313-1314.

12 Amy JJ, Van Liederkerke D: Gynaecological monitoring during tamoxifen therapy (letter). Lancet 1995;345:253-254.

13 Schwartz LB, Snyder J, Horan C, Porges RF, Nachtigall LE, Goldstein SR: The use of transvaginal ultrasound and saline infusion sonohysteroscopy for the evaluation of asymptomatic postmenopausal breast cancer patients on tamoxifen. Ultrasound Obstet Gynecol 1998; 11:48-53.

14 Ismail SM: Pathology of endometrium treated with tamoxifen. J Clin Pathol 1994;47:827833.
15 Benedet JL, Pecorelli S: Staging Classifications and Clinical Practice Guidelines of Gynecologic Cancers by the FIGO Committee on Gynecologic Oncology. Amsterdam, Elsevier, 2000

16 Barakat RR, Gilewski TA, Almadrones L, Saigo PE, Venkatraman E, Hudis C, Hoskins WJ: Effect of adjuvant tamoxifen on the endometrium in women with breast cancer: A prospective study using office endometrial biopsy. J Clin Oncol 2000;18:3459-3463.

17 Lahti E, Blanco G, Kauppila A, Apaja-Sarkkinen M, Taskinen PJ, Laatikainen T: Endometrial changes in postmenopausal breast cancer patients receiving tamoxifen. Obstet Gynecol 1993;81:660-664.

18 Neven P, DeMuylder X, Van Belle Y, Vanderick G, De Muylder E: Tamoxifen and the uterus and endometrium. Lancet 1989;i:375-376.

19 Cohen I, Rosen DJ, Shapira J, Cordoba M, Gilboa S, Altaras MM, Yigael D, Beyth Y: Endometrial changes in postmenopausal women treated with tamoxifen for breast cancer. $\mathrm{Br} \mathrm{J}$ Obstet Gynaecol 1993;100:567-570.

20 Decensi A, Fontana V, Bruno S, Gustavino C, Gatteschi B, Costa A: Effect of tamoxifen on endometrial proliferation. J Clin Oncol 1996; 14:434-440.

21 Early Breast Cancer Trialists' Collaborative Group: Effects adjuvant of tamoxifen and cytotoxic therapy on mortality in early breast cancer: An overview of 61 randomized trials among 28,896 women. N Engl J Med 1988; 319:1681-1692. 